\title{
JUDICIALIZAÇÃO DAS RELAÇÕES SOCIAIS: Uma Análise do Processo Judicializante da Lei Maria da Penha à Luz de Theophilos Rifiotis
}

\author{
http://dx.doi.org/10.21527/2176-6622.2021.55.278-285
}

Recebido em: 19/12/2019

Modificações solicitadas em: 20/4/2020

Aceito em: 21/7/2020

Vivian Paes Galvani

Universidade do Planalto Catarinense - Uniplac. Av. Mal. Castelo Branco, 170 - Universitário. CEP 88509-900. Lages/SC, Brasil. http://lattes.cnpq.br/8995172624574092. https://orcid.org/0000-0001-7742-0431. viviangalvani@hotmail.com

Mareli Eliane Graupe Universidade do Planalto Catarinense - Uniplac. Lages/SC, Brasil.

\section{RESUMO}

O presente artigo objetiva refletir acerca dos processos de judicialização das relações sociais, mais especificamente sobre a Lei Maria da Penha, no 11.340/2006, tendo por base os trabalhos do autor Theophilos Rifiotis. É importante compreender as origens do fenômeno da judicialização, das violências de gênero contra as mulheres e das reivindicações e manifestações da sociedade perante as situações de descaso estatal, em conformidade com a demanda de combate à impunidade. É uma pesquisa de abordagem qualitativa e foi utilizado o método de pesquisa bibliográfica, a partir do estudo do conceito de judicialização e de pesquisa documental, por meio da análise da Lei Maria da Penha. Os dados apontam que é importante questionar a proliferação da perspectiva primária penalizante e investir nas estratégias e nas ações de prevenção e enfrentamento da violência de gênero.

Palavras-chave: Violência de gênero contra as mulheres. Lei Maria da Penha. Judicialização.

\section{JUDICIALIZATION OF SOCIAL RELATIONS: AN ANALYSIS OF THE JUDICIALIZING PROCESS} OF THE MARIA DA PENHA LAW IN THE LIGHT OF THEOPHILOS RIFIOTIS

\section{ABSTRACT}

This article aims to develop reflections about the judicialization process of social relationships, especially about the Maria da Penha Law, which is elucidated by Theophilos Rifiotis' works. The qualitative research leads to understanding its effects progression about gender violence against women. It either pretends to assimilate the origins of the judicialization phenomenon in social revindication and manifestation towards the state neglect, following the fight against impunity request. Therefore, a bibliographic and a documental review were conducted, through the study about the judicialization concept and the analysis of the Maria da Penha Law. The research points out that it is important to question the proliferation of the penalizing primary perspective and to contribute to the gender violence prevention actions.

Keywords: Gender violence against women. Maria da Penha Law. Judicialization.

\section{SUMÁRIO}

1 Apresentação. 2 Discurso sobre judicialização. 3 Identificação do sujeito de direitos. 4 Judicialização dos conflitos de violência de gênero contra a mulher. 5 Desenvolvimento da judicialização a partir da criação da Lei Maria da Penha. 6 Considerações finais. 7 Referências. 


\section{APRESENTAÇÃO}

O fenômeno da judicialização tornou-se objeto de estudo por autores que buscam identificar os sintomas da atuação dos operadores do Direito do poder Judiciário no que tange às relações sociais. Entre os autores, Theophilos Rifiotis destaca-se por sua abordagem a respeito da temática da judicialização.

Ao refletir sobre sua origem, Rifiotis identifica o caráter reivindicatório no desenvolvimento do processo de judicialização, uma vez que provém de manifestações e requerimentos sociais, pressupondo, portanto, que a conquista de direitos ocorre por meio do reconhecimento jurídico.

Nesse sentido, o presente artigo utiliza os métodos de pesquisa bibliográfica e documental, partindo dos estudos sobre o conceito de judicialização, aliados à análise do processo de criação da Lei Maria da Penha. Assim, abordam-se os efeitos do fenômeno da judicialização referentes às práticas dos juristas quando estes se deparam com os cuidados exigidos pelas complexidades dos litígios de problemas sociais, como é o caso da violência de gênero contra as mulheres.

Primeiramente, nas duas seções iniciais do texto, são introduzidos os estudos sobre o fenômeno da judicialização em conformidade com a identificação dos sujeitos de Direito, fundamentados pelo entendimento do autor Theophilos Rifiotis. Nas duas últimas seções faz-se uma análise do processo de judicialização atrelado à temática da violência de gênero contra as mulheres e ao desenvolvimento da Lei Maria da Penha, considerando que essas abordagens demandam flexibilidade do entendimento jurídico para evitar a padronização das relações de violência.

\section{DISCURSO SOBRE JUDICIALIZAÇÃO}

Segundo Theophilos Rifiotis (2012, p. 30-31), judicialização é o privilégio das leituras jurídicas como forma de resolução de conflitos interpessoais, ampliando a articulação do sistema judiciário e desvalorizando outras formas de dirimir litígios. Esse contexto desenvolve-se por meio de mecanismos que dinamizam a atuação do Estado perante as reivindicações de movimentos sociais. Logo, o requerimento por respaldo jurídico e pela criminalização torna-se um comportamento comum da sociedade quanto aos conflitos sociais gerados. De acordo com o entendimento de Rifiotis, Vieira e Dassi quanto à semântica desses termos:

De fato, a semântica jurídica e a criminalização têm uma forte capacidade catalisadora de movimentos sociais. Há grupos que reivindicam a criminalização do aborto, do uso de substâncias psicoativas, da homofobia, do bullying etc. Em uma palavra: volúpia punitiva num quadro de falência do sistema prisional (2016, p. 36).

Conforme se observa, o fenômeno sinalizado pelos autores acarreta a inflação do poder Judiciário quando se utiliza este como ente primário à solução de problemas, inclusive de esfera pública, contribuindo para a chamada "judicialização da política". Nas palavras de Débora Alves Maciel e Andrei Koerner (2002, p. 114):

A judicialização da política requer que operadores da lei prefiram participar da policy-making a deixá-la ao critério de políticos e administradores e, em sua dinâmica, ela própria implicaria papel político mais positivo da decisão judicial do que aquele envolvido em uma não decisão. Daí que a idéia de judicialização envolve tanto a dimensão procedimental quanto substantiva do exercício das funções judiciais.

No caso assinalado pelos autores, a função do operador do Judiciário passa a ter um caráter mais arbitrário e distancia-se da característica da imparcialidade, consequentemente, da neutralidade, uma vez que, conforme o efeito da judicialização, os juristas acabam por atuar além das situações de caráter decisório, expandindo o método de decisão judicial nas disposições de caráter público. Nesse ensejo, "[...] a noção de politização da Justiça destaca os valores e preferências políticas dos atores judiciais como condição e efeito da expansão do poder das Cortes" (MACIEL; KOERNER, 2002, p. 114).

Ainda segundo Maciel e Koerner, os juristas usam o conceito de judicialização para "[...] denominar a obrigação legal de um certo tema que é analisado judicialmente com um caráter normativo", portanto, "[...] afirma-se que judicialização é o ingresso em juízo de determinada causa, que indicaria certa preferência do autor por esse tipo de via" (2002, p. 115). 
A questão conflitante dos sinais da judicialização reside no fato de que o poder Judiciário, em realidade, busca sanar apenas conflitos interpessoais e privados, não sendo, este ente, o responsável por solucionar problemas estruturais da sociedade, como é o caso da violência de gênero contra as mulheres, por exemplo. Neste viés, a responsabilidade dos juristas torna-se o principal recurso utilizado pela sociedade, limitando o auxílio ofertado pelo Estado e reforçando a premissa de que o poder Judiciário é o ente sanador de todos os tipos de litígios.

\section{IDENTIFICAÇÃO DO SUJEITO DE DIREITOS}

Para compreender o fenômeno da judicialização, faz-se importante conhecer quem é o sujeito de direitos e o diferenciar dos direitos do sujeito. $O$ primeiro não remete apenas a um indivíduo ou à pessoa. Conforme a conceitualização de Theophilos Rifiotis (2014a, p. 125), "[...] o sujeito não se reduz a um ator com um background a partir do qual ele organiza e realiza as suas práticas". Em outras palavras, não se limita à especificidade de uma situação concreta, por englobar vivências interligadas aos problemas sociais decorrentes de uma conjuntura política e cultural.

Desse modo, distingue-se da concessão de direitos atribuída pelo Judiciário a quem este ente considera o sujeito do fato existente, pois "[...] o sujeito de direitos está intimamente ligado à própria constituição da legitimidade das relações sociais no mundo moderno" (RIFIOTIS, 2014a, p. 126).

A Declaração Universal dos Direitos Humanos de 1948, por exemplo, ratifica o papel dos sujeitos de direitos em âmbito mundial, estabelecendo condições básicas às quais qualquer pessoa tem direito de dispor para viver minimamente bem na sociedade, tanto no que tange à questão da subsistência quanto da cidadania. De acordo com Rifiotis,

[...] a configuração do sujeito está em estreita correspondência com um jogo tácito, uma estratégia de estar no mundo que tem implicações sobre o exercício de cidadania e que não pode estar ausente no debate sobre direitos humanos (RIFIOTIS, 2007 apud RIFIOTIS, 2014a, p. 126).

Os conceitos relacionados pelo autor concernentes aos direitos sucedem no reforço da centralização do poder Judiciário, pois, na atualidade, a sociedade busca reivindicar seus direitos por meio do reconhecimento jurídico e entende a legislação de caráter punitivista como ferramenta de mudança social.

Um exemplo desse contexto corresponde ao recente debate sobre a criminalização da homofobia ocorrida no Supremo Tribunal Federal. ${ }^{1}$ Como resultado das discussões, foi aprovado pelo referido órgão, por 8 votos a 3, que a conduta homofóbica seja punida nas formas da Lei do Racismo (Lei no 7.716/1989). Esta prevê o crime como inafiançável e imprescritivel, com a punição de 1 a 5 anos de prisão ou multa. ${ }^{2}$ Alguns dos ministros explanaram que a inércia dos órgãos legislativos em cuidar do tema e avaliar outros meios não punitivos para dirimir o problema da homofobia caracterizam a omissão desses entes, considerando-se que caberia ao poder Legislativo desenvolver mecanismos para evitar sua repercussão. De acordo com Rifiotis:

A centralidade no campo do Direito nos leva a considerar que nos arranjos jurídicos e processuais dominam leituras criminalizantes e estigmatizadas contidas na polaridade vítima/agressor que se estende em domínios cada vez mais amplos das relações sociais (RIFIOTIS, 2008 apud RIFIOTIS, 2014a, p. 128).

Por esse viés, há um recorrente discurso sobre o comportamento que o Supremo Tribunal Federal detém em legislar sobre questões que não são de sua responsabilidade, considerando-se que a esse órgão compete resguardar e interpretar as normas constitucionais.

Como visto, a inércia dos entes competentes ocasiona na utilização do Judiciário como o meio principal em resolver conflitos. Assim, predispõe, consequentemente, o caráter punitivo do Estado, uma vez que a Corte Suprema do Judiciário apenas atua de forma interpretativa aos litígios que lhe são apresentados, mesmo quando não resolvidos anteriormente.

\footnotetext{
${ }^{1}$ Ação Direta de Inconstitucionalidade por Omissão (ADO) no 26, rel. Min. Celso de Mello, e Mandado de Injunção (MI) no 4733, rel. Min. Edson Fachin

2 Sanção patrimonial que pode ser cobrada de forma isolada ou cumulada com a pena de prisão.
} 
Conforme essa percepção, é possível assimilar o fenômeno da judicialização ${ }^{3}$ na seara da violência de gênero contra as mulheres ${ }^{4}$ tendo em vista que esse problema social demanda uma compreensão mais cautelosa do caso concreto e o seu respaldo jurídico se originou nas manifestações de combate à impunidade, como veremos posteriormente nesse artigo.

\section{JUDICIALIZAÇÃO DOS CONFLITOS DE VIOLÊNCIA DE GÊNERO CONTRA A MULHER}

De acordo com o estudo realizado por Theophilos Rifiotis, Regina Ingrid Bragagnolo e Mara Coelho de Souza Lago (2015), há disparidade entre alguns magistrados na condução de Audiências de Ratificação, cujo objetivo é decidir se a vítima de violência doméstica tem ou não interesse em prosseguir com o processo. Em audiências relativas a esses casos, foram constatados diferentes estilos no modo de produção de justiça pelos agentes do Judiciário, identificados como "tutelar", "arbitral" e "reparação moral", dos quais abordaremos os dois primeiros.

O estilo "tutelar" remete à mulher em situação de violência como sujeito incapaz e passivo, que precisa ser tutelado, distanciando a vítima do papel de sujeito de direitos "[...] que atua diante de lógicas externas, avaliando-as, situando-as e operando concretamente com elas no seu cotidiano" (RIFIOTIS; VIEIRA; DASSI, 2016, p. 39). Dessa forma, o protagonismo do sujeito de direitos recorrentemente é afastado da mulher em situação de violência, reduzindo-a ao papel de mãe ou de "mulher de alguém", com a sua imagem atrelada e dependente do comportamento social que lhe é cobrado pelo contexto em que vive.

Muitas vezes, esse costume social é repercutido pelos agentes que deveriam amparar a vítima, assim como é abordado pelo trabalho feito pelos autores ao verificar o estilo "arbitral" do magistrado, que tende a instruir e determinar o comportamento de homens e mulheres envolvidos no ambiente da violência a partir dos seus papéis sociais, o que inclui, ainda, a classe social dos sujeitos da conjuntura. Nas palavras de Rifiotis, Bragagnolo e Lago:

A própria causa algumas vezes era deixada para um segundo plano, quando se focava a representação da muIher e do homem atrelada ao desempenho dos papéis materno e paterno, por exemplo. Casos de "violência doméstica e familiar" contra a mulher foram, por vezes, reduzidos a questões de parentalidade e a outras questões morais, ficando em segundo plano o móvel que originou a própria audiência $(2015$, s.p.).

Destarte, considerando-se o exposto pelos autores, depreende-se que o desenvolvimento da judicialização cria polaridades no campo dos conflitos interpessoais, resultando na configuração de uma tendência de criminalização na análise da violência conjugal, por exemplo, a partir do estigma de vítima-agressor ou na figura jurídica do "réu" (RIFIOTIS, 2004 apud RIFIOTIS; VIEIRA, 2012).

Nesse caso, alguns mecanismos provindos do sistema judiciário demonstram a efetivação dos sintomas da judicialização, a exemplo da criação das polícias judiciais, por meio das delegacias especializadas em violência doméstica, as chamadas Delegacias da Mulher. ${ }^{5}$ Estas adotam ações de amparo à vítima e buscam inibir a situação de violência, o que não impede a repercussão desse problema social, pois não configura dever do Judiciário, nem da polícia, o desenvolvimento de políticas públicas que visem a reeducar a sociedade.

Conforme Theophilos Rifiotis (2008), o descaso com a elaboração e efetivação de políticas públicas de prevenção das violências de gênero dificulta a atuação da polícia, por limitar, por exemplo, seu desempenho e criar um ciclo de violência conforme a reincidência de casos.

O fenômeno da judicialização na seara da violência de gênero contra a mulher é um tema delicado, haja vista que a maioria da sociedade entende o poder Judiciário como o órgão capaz para resolver todos os tipos de questões conflituosas. Essa percepção social deve-se à existência de poucas políticas públicas alternativas, cujo resultado consiste na continuidade do problema e na repetição da violência doméstica.

\footnotetext{
3 Para aprofundamento sobre esse tema recomenda-se: Um olhar antropológico sobre violência e justiça: etnografias, ensaios e estudos de narrativas (RIFIOTIS; VIEIRA. Florianópolis. Ed. Da UFSC, 2012).

4 Usamos a expressão violência de gênero contra as mulheres porque é um conceito amplo e inclui todas as formas de violência vivenciadas pelas mulheres no contexto privado e público.

5 A primeira Delegacia de Defesa da Mulher (DDM) foi criada em 6 de agosto de 1985 no Estado de São Paulo.
} 


\section{Debate}

Em decorrência dos fatores arrolados, constantemente a ofendida entende que levar o litígio para o Judiciário consiste em ferramenta de "correção" para o agressor, acreditando que as agressões podem cessar, situação decorrente da ausência de meios alternativos que viabilizariam a resolução dos conflitos. Esse comportamento, no entanto, acaba gerando um ciclo, pois não reeduca as partes envolvidas na situação de violência e, por consequência, reprisa as ocorrências dos processos judiciais.

Cumpre ressaltar que as lutas pela judicialização das violências de gênero são permeadas pelo reconhecimento da igualdade dos cidadãos. A Constituição Federal de 1988 caracteriza um marco neste contexto ao situar a gravidade da violência doméstica e normatizar a necessidade da efetivação da igualdade entre homens e mulheres. No texto Constitucional, o artigo 226 trata especificamente do fenômeno, em seu parágrafo 8, ao ressaltar que "[...] o Estado assegurará a assistência à família na pessoa de cada um dos que a integram, criando mecanismos para coibir a violência no âmbito de suas relações" (BRASIL, 1988). Tendo isso em vista, na seção seguinte será aprofundado o estudo sobre os processos de judicialização das violências de gênero após a aprovação da Lei Maria da Penha.

\section{DESENVOLVIMENTO DA JUDICIALIZAÇÃO A PARTIR DA CRIAÇÃO DA LEI MARIA DA PENHA}

A elaboração da Lei 11.340, de 2006, foi corroborada por meio da recomendação do Relatório anual n. 54/2001, da Comissão Interamericana de Direitos Humanos, que tratou sobre o descaso do Estado brasileiro com a situação da violência conjugal à qual Maria da Penha Maia Fernandes esteve submetida. Esse documento advertiu sobre a importância do amparo e da proteção da vítima em caso de violência doméstica, bem como ratificou o tratamento desse tipo de violência como um problema estruturalmente social, não sendo configurado como casos privados e individuais da sociedade.

A Organização Interamericana de Direitos Humanos da Organização dos Estados Americanos recebeu a denúncia de Maria da Penha, conjuntamente com o Centro pela Justiça e pelo Direito Internacional (Cejil) e o Comitê Latino-Americano de Defesa dos Direitos da Mulher (Cladem). Esses órgãos depararam-se com a tolerância do Estado brasileiro em relação aos recorrentes episódios de violência cometidos por Marco Antônio Heredia Viveiros, então marido de Maria da Penha, que culminaram, entre outras agressões, em uma tentativa de homicídio e uma de eletrocussão.

A partir do Relatório, foi aprovada e sancionada a referida Lei, que legitima a criação de mecanismos que auxiliem na prevenção e evitem a deliberação desse problema social, bem como reconhece o tratamento jurídico específico que o problema demanda. Também definiu esse tipo de violência como qualquer tipo de ação ou omissão violenta baseada na discriminação de gênero.

Sendo assim, como consequência da necessidade de cuidados jurídicos na problemática da violência doméstica, além da ativa reivindicação popular ao combate da impunidade nesses casos, destacou-se a preponderância da concepção penal nas vias judiciais, desconsiderando a análise extrajudicial para solucionar conflitos dessa ordem. Nas observações de Rifiotis:

De um lado teríamos uma tendência, digamos, relacional, voltada ao trabalho com os agressores, a mediação, a busca de soluções extrajudiciais, etc. De outro, uma ênfase na dimensão penal, da responsabilização legal (RIFIOTIS, 2008b, s.p.).

Embora se tenha apresentado situações relativas à legislação concernente à violência contra a mulher, não configura objetivo deste artigo criticar os meios legais de punição aos agressores. Isso porque a Lei Maria da Penha resulta de diversas motivações, oriundas de variados grupos sociais que se posicionaram diante do cenário de descaso das autoridades ao tolerar os diferentes tipos de violência. Entende-se, portanto, que essa Lei demonstra avanços sociais no sentido de formalizar a condição da mulher como sujeito de direitos, portanto deve ser enaltecida como ferramenta de mudança social.

É válida, entretanto, a análise voltada ao fenômeno da judicialização nos desdobramentos dos efeitos da referida Lei desde sua promulgação, uma vez que foi sancionada num contexto social complexo, que buscava respostas para combater a impunidade. Por consequência, essa norma moldou o caráter pró-criminalizante dos mecanismos de prevenir e resolver esses conflitos e resumiu a Lei ao tipo de combate essencialmente penal. Em análise, para Machado: 
O contexto nacional foi marcado por uma dimensão normativo-penal em que a demanda pró-criminalização cresceu e ganhou tanta evidência que, muitas vezes, a lei é referida como se resumida a esse nível de resposta à questão das violências doméstica e intrafamiliares contra mulheres (MACHADO, 2014, s.p.).

Cabe ressaltar que a judicialização sob o prisma da Lei Maria da Penha é caracterizada por um reforço na estrutura judicial ofertada pelo Estado quando se defronta com um caso concreto. Como exemplo, oferece apoio, por meio de delegacias especializadas em violência doméstica, bem como garante a celeridade do processo, uma vez que, em até 48 horas, o juiz deve receber a notícia do crime pela delegacia e expedir uma medida protetiva, caso necessário. Ainda, conforme a edição da Lei no 13.827, de 13 de maio de 2019, permite-se que os próprios delegados ou policiais apliquem a medida protetiva de urgência em cidades que não sediam Comarcas, caso o risco seja iminente à mulher e/ou aos seus filhos.

Reitera-se que essa celeridade processual é o produto de reivindicações sociais que atuam para garantir os direitos das mulheres no Brasil. Tem, ainda, como característica principal, a rede de judicialização que ultrapassa o caráter meramente retributivo da Lei, pois também garante mecanismos de proteção.

Segundo Machado (2014), o problema da crítica jurídica feita à Lei Maria da Penha é o foco normativo-penal das leituras voltadas ao texto legal, uma vez que as dimensões de violência abrangem não só a esfera jurídica de caráter penalizante, pois não é exclusividade do Judiciário tratar sobre o problema de violência doméstica.

A crítica de Theophilos Rifiotis (2008) sobre a judicialização das relações sociais apresenta a dualidade dessa problemática. Evidente é que o reconhecimento jurídico representa uma visibilidade conquistada pelos respectivos movimentos sociais e legitima a luta desses grupos por seus protagonismos como sujeitos de direitos.

Esse fenômeno, todavia, também caracteriza a expansão do Judiciário e sua consequente criminalização primária da violência conjugal, estabelecendo o padrão do sistema de polarização desse tipo de violência, limitado pelo campo de "vítima-agressor". Nesse prisma, Rifiotis entende que:

O processo penal domestica por assim dizer a conflitualidade, organizando-a numa polaridade excludente, típica do princípio do contraditório no processo penal, traduzindo em categorias jurídicas polares a complexidade das relações de gênero $(2008$, s.p.).

No contexto relacionado, o movimento feminista utilizou o reconhecimento jurídico como estratégia política para efetivar sua luta no meio Judiciário, pressionando o Estado a desenvolver uma lei específica que considere a violência doméstica como um problema social. A generalização dos mecanismos penais, contudo, torna-se uma estrutura problemática ao apresentar rigidez no tratamento das especificidades e complexidades das violências doméstica e de gênero.

Essa propagação penal, conforme entende Rifiotis, refere-se "[...] ao fato de o direito operar pela tradução de conflitos através de um equivalente geral (um tipo penal, por exemplo) e a partir dele definir uma modalidade de prova ou enfrentamento legal a ser seguida" (RIFIOTIS, 2008, s.p.).

Sob o viés apresentado, o processo da judicialização, nas palavras de Theophilos Rifiotis (2008, s.p.), "[...] não deve ser considerado um fim em si mesmo e tampouco os objetivos sociais projetados sobre ele se realizam automaticamente, devendo ser objeto de monitoramento contínuo, como condição necessária para a sua efetividade".

Observa-se, nesse contexto, uma contrariedade advinda do comportamento espontâneo do Estado em judicializar de forma penalizante os problemas sociais reclamados e reivindicados por manifestações sociais, uma vez que "[...] a lei penal não deve ser vista como a primeira opção (prima ratio) do legislador para compor conflitos existentes em sociedade" (NUCCl, 2019, p. 27). À vista disso, o processo de judicialização deve ser apresentado como um último recurso do Estado em solucionar os litígios sociais, sendo monitorado para garantir sua eficiência.

\section{CONSIDERAÇÕES FINAIS}

Ao explanar sobre os efeitos da judicialização, apreende-se a fonte genitora desse fenômeno, uma vez que as reivindicações e demandas populares respaldam as exigências protestadas no ordenamento jurídico, por meio da criação de novas leis e normas que garantem o reconhecimento dos respectivos sujeitos de direitos. 


\section{Direito自

As exigências de movimentos sociais para combater as violências de gênero contra as mulheres originam, por consequência, a inclinação penalizante e pró-criminalizante da compreensão jurídica sobre os litígios, desenvolvendo, os juristas, uma análise mais rígida e inflexível das complexidades que cada problema social sustenta. Como apresentado no presente trabalho, as especificidades que abrangem a relação de violência de gênero contra a mulher não se resumem aos polos vítima e agressor.

Segundo Theophilos Rifiotis (2008), a fragmentação dos sujeitos faz com que o reconhecimento esteja em movimento e necessite de novos modos de avaliar justiças e injustiças. Sendo assim, desenvolver ações de prevenção da violência de gênero contra as mulheres e que visem a estabelecer condições mais equitativas é de suma importância para constituir mecanismos eficazes que evitem a propagação da tendência criminalizante.

Destarte, não é objetivo neste estudo criticar a (in)eficiência do Direito e de seu ordenamento jurídico, pois ambos representam mecanismos de mudança social e acolhem requerimentos da sociedade. Com a finalidade, todavia, de manter sua plena eficiência e não se distanciar do caráter reivindicador, o Direito e os processos judicializantes devem ser objetos de monitoramento constante, assegurando, por assim dizer, sua competência em garantir os direitos e os deveres da sociedade.

Enfim, esta análise relaciona a importância da criação e instituição de políticas públicas de prevenção e enfrentamento às violências de gênero contra as mulheres nas diversas áreas do conhecimento, a exemplo, entre outras, da educação, da cultura, da religião, das mídias e da saúde. Isso porque entende-se que a construção das identidades de gênero deve prescindir de um modelo que reproduz o machismo, o patriarcado, a supremacia do homem e a submissão e inferioridade da mulher.

Esse modelo patriarcal não se compatibiliza com os princípios dos direitos humanos fundamentais para as mulheres, além de estar em conflito com o projeto de construção de uma sociedade mais justa e igualitária. Consequentemente, a violência de gênero contra as mulheres afeta a família, as crianças, e causa sequelas e traumas nas vítimas, além de interferir na saúde física, mental e psicológica de toda a estrutura familiar.

$\mathrm{Na}$ tentativa de amenizar esse problema, entende-se a necessidade de investimentos em estratégias e ações de prevenção e enfrentamento de violências de gênero com o objetivo de construir, com as novas gerações, outros valores, comportamentos e cultura, cujos princípios orientem que meninas e mulheres sejam respeitadas como cidadãs e sujeitos de direitos em todas as instâncias da sociedade. Essas ações são importantes para que não reste às mulheres apenas a via judicializante da violência de gênero.

\section{REFERÊNCIAS}

BRASIL. BRASIL. Constituição Federal de 1988. Promulgada em 5 de outubro de 1988. Disponível em: http://www.planalto.gov. br/ccivil_03/constituicao/constituição.htm.

BRASIL. Presidência da República. Lei № 13.827, de 13 de maio 2019, Lei Maria da Penha. Disponível em: http://www.planalto. gov.br/ccivil_03/_ato2019-2022/2019/lei/L13827.htm. Acesso em: 3 ago. 2019.

COMISSÃO INTERAMERICANA DE DIREITOS HUMANOS. Organização dos Estados Americanos. Relatório $n^{\circ} 54 / 01$ Caso 12.051 - Maria da Penha Maia Fernandes - Brasil. 4 abr. 2001. Disponível em: https://www.cidh.oas.org/annualrep/2000port/12051. htm. Acesso em: 10 ago. 2019.

CORREA, Ranna Mirthes Sousa. Lei Maria da Penha e a Judicialização da violência doméstica contra a mulher nos Juizados do Distrito Federal: um estudo de caso na Estrutural. Brasília. UnB, 2014. Disponível em: http://www.29rba.abant.org.br/resources/anais/1/1401762653_ARQUIVO_ArtigoRBA.pdf. Acesso em: 1o ago. 2019.

MACHADO, Isadora Vier. Para além da judicialização: uma leitura da Lei Maria Da Penha (Lei n 11.340/06) em três dimensões. Feminismos, 2014. Disponível em: https://portalseer.ufba.br/index.php/feminismos/article/view/29977/17727. Acesso em: 2 ago. 2019.

MACIEL, Débora Alves; KOERNER, Andrei. Sentidos da judicialização da política: duas análises. Lua Nova, n. 57, 2002.

NUCCI, Guilherme de Souza. Manual de Direito Penal. 15. ed. Rio de Janeiro: Forense, 2019.

RIFIOTIS, Theophilos; BRAGAGNOLO, Regina Ingrid; LAGO, Mara Coelho de Souza. Estudo dos modos de produção de justiça da Lei Maria da Penha em Santa Catarina. Florianópolis. Revista Estudos Feministas, v. 23, n. 2, p. 601-617, maio/ago. 2015.

RIFIOTIS, Theophilos. Judiciarização das relações sociais e estratégias de reconhecimento: repensando a "violência conjugal" e a "violência intrafamiliar". 2008. Disponível em: http://www.scielo.br/scielo.php?script=sci_arttext\&pid=S1414-49802008000200008\&lng=pt\&tlng=pt. Acesso em: 31 jul. 2019. 
RIFIOTIS, Theophilos. Judicialização dos direitos humanos, lutas por reconhecimento e políticas públicas no Brasil: configurações de sujeito. Revista de Antropologia, USP, São paulo, v. 57, n. 1, p. 119-144, 2014a.

RIFIOTIS, Theophilos; VIEIRA, Danielli; DASSI, Tatiana. Judicialização das relações sociais e configurações de sujeito entre jovens cumprindo medidas socioeducativas em Santa Catarina. Anuário Antropológico, on-line, I, 2016. Disponível em: http://journals.openedition.org/aa/1564. Acesso em: 5 ago. 2019.

RIFIOTIS, Theophilos; VIEIRA, Danielli. Um olhar antropológico sobre violência e justiça: etnografias, ensaios e estudos de narrativas. Florianópolis. Ed. Da UFSC, 2012.

RIFIOTIS, Theophilos. Violência, Justiça e Direitos Humanos: reflexões sobre a judicialização das relações sociais no campo da "violência de gênero." 2014b. Disponível em: http://www.scielo.br/pdf/cpa/n45/0104-8333-cpa-45-00261.pdf. Acesso em: 5 ago. 2019. 